\title{
Assessment - An Important Facet of Learning
}

\author{
Shradha Kanwar \\ NIIT University, India
}

\begin{abstract}
Education is undergoing a phenomenal transformation. ICT has penetrated and broken all barriers in the teaching-learning process. The millennial generation is no longer a silent participant in the educational realm. As societal changes exhibit dominance of digital innovations, most people in the cohort of educators understand the need to sense the tide and direct the flow of the change. The critical area of assessment is also changing in this dynamic e-space. The change is visible in not in the inclusion of technology in conducting the assessment process but also in -what should be assessed. The new era learners need to be assessed on high order thinking skills and not merely knowledge acquisition.

Assessment is an important tool to gauge the effectiveness of a learning process. In the era of $21^{\text {st }}$ Century skills and versatile learning, the assessment formats should not conform to traditional standards of mapping learning potential. It is imperative to devise the right kind of assessment that strikes a chord with the learner, where they are not passive recipients of information but dynamic contributors in directing their learning curve and designing the learning process. At the same time optimal education sense should ensure that utopian impulses are matched with practical demands. This paper is an elucidation into the present assessment trends and the innovative suggestions in the field of assessment that could make a huge impact in creating learners of a higher order. It builds on the discussions entailed in a previous research that highlighted the importance of personalized learning as an improvement intervention in the curriculum and pedagogy. The paper discusses the importance of technology in improvising our assessment approach and defining better learning standards. This shall be the revolutionary trend of assessments, where the learners establish their own potential through selflearning and active participation in the assessment process.
\end{abstract}

\section{Introduction}

The contemporary educational scenario has been hugely impacted by heterogeneous set of changes. These include globalization, economic flux, turbulence in the societal norms, and most importantly the invasion of technology in every stream of the teaching-learning process.

This is the era of educational liberalization. ICT has penetrated and broken all barriers in the teaching-learning process. The millennial generation is no longer a silent participant in the educational realm. As societal changes exhibit dominance of digital innovations, most people in the cohort of educators understand the need to sense the tide and direct the flow in the overall educational ethos. Research on various fronts has established the need for educators to focus on implementing newer content generation strategies and pedagogical innovations, but the need for a smarter assessment blueprint remains overlooked or underestimated.

In order for the educational process to become more effective, one needs to take maximum advantage of inclusion of technology in the assessment area. Assessment is an important tool to gauge the effectiveness of a learning process. According to Martell and Calderon, assessment is an ongoing process that involves planning, discussion, consensus building, reflection, measuring, analyzing, and improving based on the data and artifacts gathered about a learning objective [1]. Assessment is that integral component of learning that is all pervasive and yet despite all the deliberations done on various fronts - the area of assessment has not been fully explored. One needs to understand that this very intricate and deliberate activity; if effectively ideated and implemented can have extraordinary results in accentuating the overall learning process.

Assessment seems largely dominated by traditional practices and educators somehow feel reluctant in experimenting with - the what and how of learning. As a consequence, assessment is still hewed to tradition and therefore not an effective mechanism in understanding today's learner needs. The essence of assessment therefore needs to be refurbished to ensure its efficacy.

The assessment process begins with the identification of learning goals and measurable objectives as well as the use of specific traits that help define the objectives being measured [2]. As curriculum and pedagogy undergo dramatic transition in sync with the changed educational environment, assessments need to become a part of the novelty. Assessment encompasses a range of 
activities including testing, performances, project ratings, and observations [3] and therefore all activities need to be replenished.

The construct of education which was traditionally teacher-centric has now become learnercentric. Accrediting agencies are beginning to require the establishment of learner-centered outcomes that reflect the well-rounded knowledge, competencies, and abilities preferred in today's students; the alignment of curriculum to reflect the desired progression and cognitive development of learners; the collection of data that demonstrates the satisfaction of learning objectives; and the use of assessment information to inform decision making [4].

This research paper elucidates the established models of assessment practices based on a review of literature. It also proposes novel formats of assessment based on the author's initiatives in the higher educational classroom.

\section{Theories and models of learning}

The process of learning is most critical in ensuring that learning goals are met. A goal takes into account the overall development and empowerment of a learner, which can be attained by establishing the right learning processes. It, therefore, follows that we focus on such a mode of assessment, which is not obsessed with outcomes and end results, but is open to a broad, continual method that ensures productive outcome. Such an assessing process is bound to be vibrant with intermittent adaptations. The assessment needs to be further strengthened on the basis of the evolving needs of the learners to ensure maximum cumulative impact.

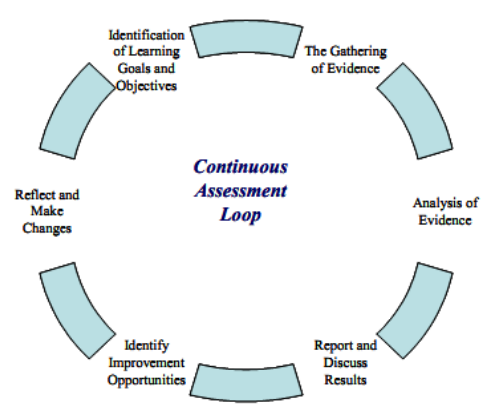

Figure 1. The Assessment Process based on Martell and Calderon, 2005

This is possible in an educational environment, where the learner has graduated into becoming a spirited participant in designing his own learning path, in keeping with his understanding of the assessment process and the definitive parameters thereof. Such an intensively dynamic mode of assessment is expected to be a practical proposition, given the advancement in information and communication technology and the emerging teaching-learning techniques in tandem with the contemporary multi media.

In order to innovate, it is important to consider the existing models of learning.

\subsection{Acquisition}

The simplest model of learning explains the acquiring of new information by the learner as a standard mechanical process. Anna Sfard argues that for thousands of years our thinking about learning has been driven by the acquisition metaphor, since we had conceived of learning as acquiring or collecting knowledge, as if it was an object, or a set of objects [5]. This can take place through reading or listening. Whereas reading enables gaining information through the visual stimulus; listening does the same through the auditory stimulus. Oral discourse resulting in learning by rote, prior to the advent of the printing press, was a common practice of acquisition of knowledge and exists even now in traditional institutes.

\subsection{Participation}

The participation metaphor of learning is more powerful than the acquisition model as it empowers the learner. Learning becomes an action point because of involvement in the knowledge enhancement process. Jean Lave and Etienne Wenger have constructed a widely utilized conceptualization of "situated learning", a view that lays emphasis on social learning through initial observation and subsequent immersion in the process [6].

\subsection{Behaviorist Theory}

The theory of behaviorism in learning has been immensely popular in the last few decades. Because of its psychological orientation, the ramifications of the behaviorist theory have gone through test and trials in the classroom. This model is based on recall of facts and performance under test conditions within certain time frames and is focused more on situational responses with limited access to learning materials.

\subsection{Cognitive Constructivist}

Constructivism as a concept existed as long back as during the time of Socrates. The theory revolves around the learner's ability to learn by constructing an experience which is more individualized than forced by external circumstances. The cognitive constructivist model is based on the assimilation of ideas, consequent to an individual's understanding, 
and on his demonstrated ability through his applied knowledge and skills. Technology has contributed tremendously to rebuilding the experiences for today's learners.

\subsection{Socio-cultural}

This form of learning is based on synthesis of knowledge through interaction with others and on the basis of learning expressed through participation in real life problems. The dynamism of the social milieu therefore has a long lasting impact on the learning process.

Different models of learning have their strengths and an intelligent educator needs to optimize the connection of these theories in the classroom environment. Traditionally, assessment was governed by the process flow: Student completes ---$\rightarrow$ teacher evaluates---- $\rightarrow$ assigns grade based on single objective. But today, learning is no longer confined to the teaching and measurement of knowledge and assimilation of ideas but has progressed to high order thinking skills that need to be measured with the right assessment tools.

\section{Redefining objectives: From Memory loci to synthesis of knowledge}

Since a long time, the traditional educational environment has focused on the retention of information by testing the memory skills. However, with the advent of technology and exponential growth of information, the brain is no longer capable of storing information. Also, the easy access of information has created improved opportunities of learning by focusing on higher order skills. Developmental concepts articulated in Bloom's Taxonomy of Educational Objectives provided a recognized set of hierarchical behaviors that can be measured as part of an assessment plan [7].

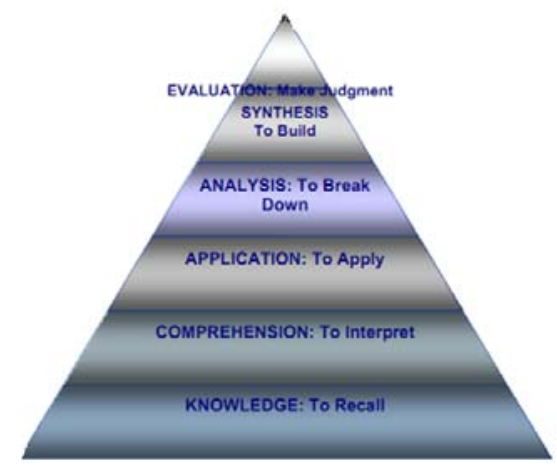

Figure 2. Bloom's Taxonomy of Educational Objectives

As the teaching-learning environment transforms, so do the objectives. Good assessment serves multiple objectives and benefits a number of stakeholders [8]. Haken explained that it is important to measure knowledge; however, measuring knowledge is not enough [9].

Hence, the current charge in education is to transform learning and assessment from the world of memorized facts to a broad, well-rounded model that reflects the learner centered outcomes of an academic program [10].

According to Dietal, Herman, and Knuth assessment provides an accurate measure of student performance to enable teachers, administrators, and other key decision makers to make effective decisions [11]. A variegated learning environment is important to excite, engage and challenge the learners and creating a robust assessment format is a process integral to this form of learning. Kellough and Kellough [12] identified seven purposes of assessment:

1. Improve student learning

2. Identify students' strengths and weaknesses

3. Review, assess, and improve the effectiveness of different teaching strategies

4. Review, assess, and improve the effectiveness of curricular programs

5. Improve teaching effectiveness

6. Provide useful administrative data that will expedite decision making

7. To communicate with stakeholders

Consistent rehearsal and practice for reinforcement of learning and memory has given way to critical thinking, synthesis and leveraging on interpersonal intelligence through collaboration and this is what needs to be assessed.

\section{Technology: An advantage}

Assessment completes the learning process, giving it meaning and the right impetus. The purpose of assessment is to build a generation of scholars, ready to excel in a dynamic competitive global world. Technology has bridged the gap between people, alleviating distance and empowering real time learning. The education environment needs to harness this technology, especially in the sphere of assessment and evaluation. Building a learning path for a technologically superior generation demands individual-centric assessment strategies, targeting individual caliber and competence. According to Vendlinski and Stevens, technology offers new measures for assessing learning that can yield rich sources of data and can expand the ways, by which educators would understand learning -mastery as well as teaching-effectiveness [13]. The use of information technologies and e-learning strategies can provide an efficient and effective means of assessing teaching cum learning-effectiveness, by supporting traditional, authentic, and alternative 
assessment-protocols [14]. There are various modes through which technology can enhance the assessment process. Networking tools encourage collaboration with experts and peers synchronously as well as asynchronously, thus allowing larger learning space. Formative assessment, summative assessment, diagnostic assessment, rubrics and project-based learning can be effectively improvised by technological interventions in the design and delivery of assessments. For institutes to evolve as benchmarks of excellence, one needs to match their functions with the societal imperatives and also take maximum advantage of the virtual environment in the field of assessment.

\section{Discussions for the future}

Assessment changes need to base on the aspirations, aptitude and interests of learners. We need a focused, smart redesign of the way assessment is looked at today, by creating an academic program that works on building as well as assessing students' critical-thinking skills.

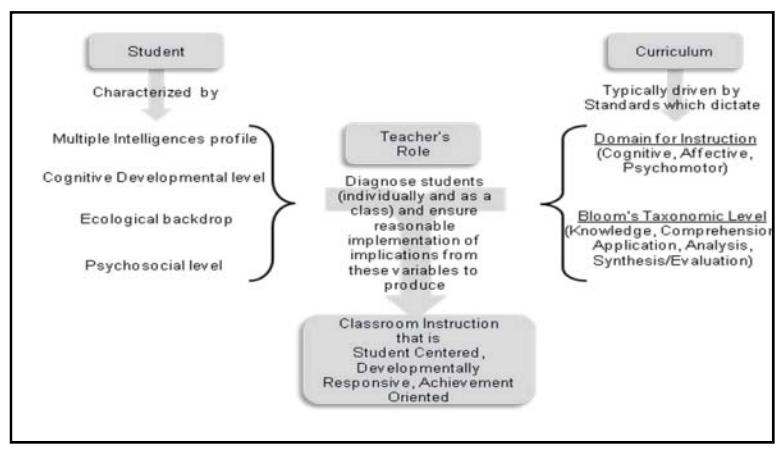

Figure 3. A Model for Balancing Classroom Instruction (Smith, 2009)

A collaborative, ubiquitous model of assessment is necessary to create a competent, confident individual with a competence of 21st century skills. Assessment needs to break the stereotype questionanswer format and it needs to be based on an analysis of cognitive themes and multiple intelligences, while retaining the academic thoroughness. Quantitative measures need to coalesce with qualitative evaluations, in order to achieve a fuller and holistic objective. The learner needs to be treated at par in the learning construct, with goals aligned towards the development of positive emotion and independent learning. The one quality that human beings possess is that of social learning, which facet needs to accentuate in the design and delivery of the assessment process. Alongside, learners need to be assessed not for the knowledge they lack, but for the knowledge they possess, by effectively leveraging their varied skillset. Feedback from learners is an important aspect of assessment, as it helps in directing the learning process in a constructive manner. Feedback also helps in matching learning outcomes with set objectives. Feedback is relatively more effective, when it provides information on correct responses rather than on incorrect ones and when it builds on changes from previous trails [15].

\section{Supporting the learning process}

While learners select their own choice from a variety of options and resources, they are stimulated to self-evaluate their interests and needs, and this process facilitates self-directed learning [16]. Assessment should also be based on this modus operandi of learning, which engages while it educates. In its continual form, assessment should be dynamic, holistic and progressive. At the same time it should target individual needs and promote high quality interactions. The traditional form of assessment comprising standardized, teacher made tests focused entirely on assigning grades but the alternative assessment mode involves creating rubrics and sharing specific performance parameters which learners can assess for themselves as well as for others.

\subsection{Assessing oneself}

The uniqueness of individuals in possessing certain intelligence and learning abilities needs to be channelized with the right assessment. Learning environments should enable learners to enhance their learning curve.

The learners can be assessed on the basis of problem based learning which Barrows defines as, the learning that results from the process of working towards the understanding of a resolution of a problem. The problem is encountered first in the learning process [17]. Problem-based Learning is part of the shift from the teaching paradigm to the learning paradigm [18].

Project-based learning is also an alternative form that helps to assess individual potential by exposing them to real time situations. Projects are complex tasks, based on challenging questions or problems that involve students in activities relating to designing, problem-solving, decision-making or investigating; that give students the opportunity to work relatively autonomously over extended periods of time; and that culminate in realistic products or presentations [19]. These two futuristic forms are gradually evolving into popular formats to assess learner's true potential.

Individual assessment can be further strengthened in an enabling virtual environment that allows analysis of multiple learning abilities. Audio learners can be trained to assess themselves through self recorded audio clips, which can then be played and 
assessed by themselves. Audio books, podcasts, audio essays and digital story telling tools are very effective in providing enriching information as well as engaging the learners through an interactive process. The assessment through these formats helps in a high achievement, result driven learning environment.

Visual and kinesthetic learners can hugely benefit from the personalized instruction mode that is a possibility with videos and visuals that enhance knowledge and develops critical thinking skills. Any integration needs to be fit for purpose and therefore, assessment in this format needs to be based on specific parameters. Teachers can use power point presentations, prezi, eBooks, glogster and other open sources on the internet that provide the necessary stimulus, keeping in mind that the assessment should be based not just on attention span and recall but on application and creation of a transformational experience.

Multiple access points of learning helps build the Cognitive Skills. Interactive case studies, infographics and webinars are some ways through which assessments can be carried out. As Knowles stated, learners "take the initiative, with or without the help of others, in diagnosing their learning needs, formulating learning goals, identifying human and materials resources for learning, choosing and implementing appropriate learning strategies, and evaluating learning outcomes” [20]. Learners can be involved in creating their portfolios which helps them to estimate their strengths, limitations and take considered decisions in understanding their learning needs. Portfolios can be used to assess learningoutcome achievement as well as to diagnose curriculum deficiencies that require improvement [21]. According to Chun, a portfolio should require students to collect, assemble, and reflect on samples that represent the culmination of their learning [22]. Cooper identified six considerations of the portfolio building process: identification of skill areas, design of measurable outcomes, identification of learning strategies, identification of performance indicators, collection of evidence, and assessment [23].

Blogging has become a very common and constructive way of self assessment. Assessment interactions are important and this is provided through blogging where student acts as an independent researcher having a purposeful conversation.

\subsection{Peer assessment}

Peer pressure defines the identity of an individual and peer assessment is a highly beneficial tool in enabling individual potential. Through peer assessment, a good learner learns to develop the right kind of interpersonal skills, develop more awareness of qualities and see work objectively. It also helps learners to understand and empathize with what others have done in the same task. Assessments need to be articulated with a thought out strategy how students make judgment on each other's work. In the same peer group there exists an element of frankness and this helps in instilling confidence during the assessment process. At the same time, adequate attention needs to be paid to the fact that utopian impulses are matched with practical demands.

Social networking has become an important inevitable influence. The Internet features communication platforms, such as blogs, wikis, and social networks that have allowed average users to change from passive receivers of information to active producers of information [24]. Learning from social networks stirs the users' imagination and synergizes their ideas. Assessments can be designed through a range of real-time, scenario-based tasks that measure an individual's ability to navigate, critically evaluate and comprehend information through digital technology.

Academic forums are important platforms to assess collaborative skills and interpersonal abilities. Not only are the cognitive abilities tested in this process but what is also encouraged and assessed is their ability to share, initiate and participate proactively in discussions. Collaboration allows learners to match their learning progression with their peers and instill the right competitive streak in them.

\subsection{Formative assessment}

The process of assessing the learning of individuals during the period of information acquisition has become even more important today. Formative assessment allows continuous and continual monitoring of an individual's insight. Formative assessment is an integral mechanism that can be strengthened through a more positive attitude to learning. There needs to be a shift from the traditional closed ended questions and open questions need to be framed to stimulate discussions. Also assessment should be feedback based and not grade based, as grades just perform the function of labeling and consequently creating a prejudice among people. Feedback on the other hand has a stronger impact on learning as it provides constructive and specific ways of improving the learning input. Quality of feedback is crucial to learning and therefore questions that are framed need to be interesting and challenging so that the learners are able to understand and implement the desired changes. Time bound assessments also enable learners to regulate themselves and learn the art of self management. 


\subsection{Summative assessment}

In the process of creating effective assessment mechanisms, it is important to reconcile different practices. Even during the process of summative assessment, it is important to focus on measurement of the process goals to ensure a holistic understanding of the skill set. The true value for learning can only be achieved if the summative assessment process takes care of diverse needs and unique learning potential along with targeting high order thinking skills.

Myriad forms of assessment can be developed and implemented by embracing technology. The innovation is important from individual educators, researchers, practitioners but the administration also plays a critical role in ensuring that such initiatives are not limited to isolated interventions but become an integral part of the academic ethos of the institute.

\section{Conclusion}

There is little precedent of new formats of assessment being effectively implemented on a large scale, yet their relevance, partly or wholly, fundamentally or blended, is a prime need of the future. This research paper aims at exploring an appropriate assessment mechanism to measure students' progress in the field of learning, particularly in digital literacy, which could empower, in an informed and inclusive educational environment. It also elucidates learners' skills across a varied spectrum of learning domains; assisting the effective crafting of future educational interventions that are in line with the predilection of modern times.

The emerging educational environment would need a model of assessment that is scalable and ubiquitous, that is based on analysis of cognitive themes and multiple intelligences and that is, at the same time, collaborative and integrated to regulate thinking. An intensive research in the area of assessment should continue to focus on the impact of the modes of assessment on learning process and overall efficacy thereof in improving the essence of the learner-teacher syndrome.

\section{References}

[1] K. Martell \& T. Calderon, Assessment of student learning in business schools: Best practices each step of the way (Vol. 1, No. 1, pp. 1-22). Tallahassee, Florida: Association for Institutional Research.

[2] Walvoord, B. E., \& Anderson, V. J. (1998). Effective grading: A tool for learning and assessment. San Francisco: Jossey-Bass
[3]Orlich, Harder, Callahan \& Gibson. (2004) Teaching strategies: A guide to better instruction. New York: Houghton Mifflin.

[4] Buzzetto-More, N. (2006, March). The eLearning and business education paradigm: Enhancing education, assessment, and accountability. Proceedings of the Maryland Business Education Association Conference. Ocean City, MD.

[5]Sfard, Anna (1998). On Two Metaphors for Learning and the Dangers of Choosing Just One. Educational Researcher, 27, (March) 4-13.

[6] Lave, Jean \& Wenger, Etienne (1991). Situated Learning - Legitimate Peripheral Participation. Cambridge: Cambridge University Press.

[7]Harich, K., Fraser, L., \& Norby, J. (2005). Taking the time to do it right. In K. Martell \& T. Calderon, Assessment of student learning in business schools: Best practices each step of the way (Vol. 1, No. 2, pp. 119-137). Tallahassee, Florida: Association for Institutional Research.

[8] Love, T. \& Cooper, T. (2004). Designing online information systems for portfolio-based assessment: Design criteria and heuristics. Journal of Information Technology Education, 3, 65-81. Available at http://jite.org/documents/Vol3/v3p065-081-127.pdf

[9] Haken, M. (2006, January). Closing the looplearning from assessment. Presentation made at the University of Maryland Eastern Shore Assessment Workshop. Princess Anne: MD.

[10]Wright, B. (2004, October 1). An assessment planning primer: Getting started at your own institution. Presentation Made at the 13th Annual Northeast Regional Teaching Workshop.

[11] Dietal, R. J., Herman, J. L., \& Knuth, R. A. (1991). What does research say about assessment? North Central Regional Educational Laboratory. Retrieved 3/27/06 from: http://www.ncrel.org/sdrs/areas/stw_esys/4assess.ht m

[12] Kellough, R.D. \& Kellough, N.G. (1999). Secondary school teaching: A guide to methods and resources; planning for competence. Upper Saddle River, New Jersey Prentice Hall.

[13]Vendlinski, T., \& Stevens, R. (2002). Assessing student problem-solving skills with complex computer based tasks. Journal of Technology, Learning, and Assessment, 1 (3). Available at http://escholarship.bc.edu/jtla/vol1/3] 
[14]Bennett, R. E. (2002). Inexorable and inevitable: The continuing story of technology and assessment. Journal of Technology, Learning, and Assessment, 1 (1). Available at http://www.jtla.org

[15]Hattie \& Timperley, 2007. The power of feedback. Review of Educational Research, 77(1), 81-112.

[16] Brockett, R. G., \& Hiemstra, R. (1985). Bridging the theory-practice in self-directed learning. In S. Brookfield (Ed.), Self-directed learning: From theory to practice. New Directions for Continuing Education (No. 25). (pp. 31-40). San Francisco: Jossey-Bass.

[17] Barrows, H. and Tamblyn, R. (1980) Problembased Learning: An Approach to Medical Education. New York: Springer.

[18]Barr, R.J. and Tagg, J. (1995) "From Teaching to Learning: A New Paradigm for Understanding Education,” Change 27, 6, 12-25.

[19] Lloyd-Jones, G. Margeston, D. and Bligh, J. (1998) "Problem-based Learning: A Coat of Many Colours,” Medical Education, 32, 492-494.

[20] Knowles, M. (1975). Self-directed learning: A guide for learners and teachers. Englewood Cliffs, NJ: Prentice Hall.

[21] Popper, E. (2005). Learning goals: The foundation of curriculum development and assessment. In K. Martell \& T. Calderon, Assessment of student learning in business schools: Best practices each step of the way (Vol. 1, No. 2, pp. 1-23). Tallahassee, Florida: Association for Institutional Research.

[22]Chun, M. (2002). Looking where the light is better: A review of the literature on assessing higher education quality. Peer Review. Winter/ Spring.

[23] Cooper, T. (1999). Portfolio assessment: A guide for lecturers, teachers, and course designers. Perth: Praxis Education.

[24] Budin, H. (2005). Democratic Education and Self-Publishing. In Crocco, M. (Ed), Social Studies and the Press: Keeping the Beast at Bay? Information Age Publishing. 